\title{
An Outcome Evaluation of Competency Based Training for Child Welfare
}

\author{
M. Elizabeth Vonk \\ W. Sean Newsome \\ Denise E. Bronson
}

\begin{abstract}
In responseto thecontinuing need for competent child welfare professionals, a large mid-western university's Coll lege of Social Work collaborated with a public child we fareagency to design and implement a oneyear, TitlelV-E-funded training opportunity for second-year MSW students. Student outcomes, including knowledge acquisition, attitudes about child welfare, and field of post-graduation employment, were evaluated using a quasi-experimental pre-post comparison group design $(n=28)$. Resultsindicated that therewerestatistically significant differences between the two groups concerning attitudes about child welfare practice. However, although trainees level of child welfare knowledge increased more than that of the comparison group, the difference did not reach statistical significance. Implicationsfor practiceand social work education are discussed.
\end{abstract}

Keywords: Child welfare, knowledge acquisition, evaluation, outcomes

$\mathrm{R}$ ecruiting and retaining social workers for child welfare careers has been a topic of significant concern both for schools of social work and child welfare institutions (Gleeson, Smith \& Dubois, 1993; Hopkins, Mudrick \& Rudolph, 1999; Jones, 2002; Larner, Stevenson \& Behrman, 1998; Lieberman, Hornby \& Russell, 1988). Social work students are often reluctant to enter public child welfare due to concerns about job stress, negative public perceptions, and working conditions. Retaining those who do enter the field has also been an issue. Retention rates in many child welfare agencies have been abysmal, resulting in a workforce comprised mostly of young, inexperienced caseworkers handling some of the most challenging and difficult cases. In addition, the cost of replacing workers is enormous, especially in terms of orientation and training (Daly, Dudley, Finnegan \& Christiansen, 2000). Nonetheless, extensive training is crucial given the increasing complexity of child welfare work (Gleeson, et al., 1993).

Attracting and retaining a cadre of professionally trained child welfare workers is complicated by a number of factors both within schools of social work and the

M. Elizabeth Vonk, MSW, Ph.D. is Associate Professor at the School of Social Work, University of Georgia, Athens, GA 30602; W. Sean Newsome, Ph.D. is Assistant Professor, Jane Addams College of Social Work, Chicago, IL 60607; and Denise E. Bronson, Ph.D. is Associate Professor, College of Social Work, Columbus, $\mathrm{OH} 43210$.

Copyright $^{\bullet} 2003$ Advances in Social Work Vol. 4 No. 2 (Fall 2003) 82-93.

Indiana University School of Social Work. 
child welfare work environment. Many social work students are reluctant to enter public child welfare, even if they have a strong interest in serving children and families. Public child welfare is often viewed as stressful, low status, and low paying (Jones, 2002; Pecora, Briar \& Zlotnik, 1989). According to numerous sources, these perceptions are not necessarily false (Curtis \& Boyd, 1996; Larner, et al., 1998; Lieberman, et al., 1988. Public scrutiny of the child welfare system by the media and the recent death of a child welfare worker during home visit in Ohio have further contributed to social work students avoiding public child welfare service.

Criticisms of social work education as it relates to the field of child welfare have also been voiced (Gleeson, et al., 1993; Lieberman, et al., 1988; Hopkins, et al., 1999). Social work education has been criticized for its lack of relevance to the actual skills and knowledge required for work within an agency. Another criticism is that social work schools have shown a lack of commitment to recruiting and educating social workers interested in working within the public sector. Suggestions for competency-based education and greater collaboration between educators and public agencies have been made in response to these criticisms (Rycus \& Hughes, 1998).

Problems within child welfare agencies also contribute to difficulties in recruiting and retaining workers. Caseloads are typically high, supervision is often weak, opportunities for promotion are limited, and policies are often changing and unclear (Guterman \& Jayaratne, 1994; Harrison, 1995; Pecora, et al., 1989; Rycraft, 1994; Vinokur-Kaplan \& Hartman, 1986). As a result, worker burnout is not uncommon and supervisors often recognize the problem too late to intervene(Anderson, 1994; Cicero-Reese \& Black, 1998; Glisson \& Hemmelgarn, 1998; Guterman \& Jayaratne, 1994). The result is that most child welfare workers do not have social work degrees and, in some states, no pre-servicetraining is provided (Larner, et al., 1998).

Despite the obvious difficulties in attracting social workers to child welfare, the evidence is clear that those with social work degrees are better prepared to serve families and children in the child welfare system. Several benefits of social work education for child welfare workers have been reported in the literature (Lieberman, et al., 1988; Hopkins, et al., 1999; Olsen \& Holmes, 1982). Those child welfare workers with formal social work training report feeling better prepared and more competent in the performance of their jobs than do non-professionally educated workers. Social work educated workers also have been reported to provide higher quality services in child welfare. In addition, the social workers report greater job satisfaction. Finally, social work education seems to increase retention of child welfare workers.

Many schools of social work, in response to the issues described above, have utilized Title IV-E money to support the training of social workers for work in child welfare (Rose, 1999). In fact, at least $24 \%$ of respondents from a recent survey of CSWE-approved (or in candidacy) social work programs indicated the use of Title IV-E money for degree-related education (Zlotnik \& Cornelius, 2000). Title IV-E training money, made available through the Child Welfare and Adoption Assistance Act of 1980 (P.L. 96-272) is intended to provide education at the undergraduate and/or graduate levels for students who plan to work in public child wel- 
fare agencies. Universities that utilize this money are expected to collaborate closely with public child welfare agencies; and students who receive funded education are expected to work in child welfare for one year upon graduation.

At least four reports have recently addressed the use of Title-IV-E monies by schools of social work. Jones (2002) presented the results of a Title IV-E program developed by the California Social Work Education Committee. She found that those with social work training had longer periods of employment in child welfare. Zlotnik and Cornelius (2000) have described the use of IV-E funding by schools of social work utilizing survey methodology. Rose (1999) described the Title IV-E Child Welfare Training Program at the University of Wisconsin-Milwaukee in relationship to adult-learning issues. In addition, they included qualitative data related to the students' evaluation of the program. Finally, Robin and Hollister (2001) examined and reported on the career development in, and contributions to, child welfare practice among 73 graduates of the University of Minnesota's Child Welfare Scholars Program. They concluded that Title IV-E monies were well spent, resulting in committed, social work trained child welfare professionals who were making many positive contributions to the field.

This paper briefly describes a Title-IV-E funded, MSW-level child welfare training program and reports on student outcomes related to knowledge acquisition, attitudes toward child welfare clients and practice, and satisfaction with the training program. After a description of the program, the outcome evaluation method and results are presented. Finally, implications for practice and social work education are discussed.

\section{PROGRAM DESCRIPTION}

The goal of the child welfare training program was to prepare a group of 14 masters-level social work students for postgraduate careers in child welfare through a collaborative effort between The Ohio State University College of Social Work (CSW) and a large, public county children's services agency (CCS). Students entering the second year of the MSW program at The Ohio State University were eligible to apply for the program. Acceptance into the traineeship required that students express a desire to work in child welfare after graduation, have an acceptable grade point average, and possess a willingness to accept a field practicum at CCS.

The organizing framework and foundation knowledge for this project came from the Field Guide to Child Welfare (1998) developed by Judy Rycus and Ron Hughes from the Institute for Human Services (IHS) in Columbus, Ohio. This is a four volume set of materials that identifies and teaches the core competencies for child welfare workers. These materials are distributed by the CWLA and are currently used as part of the Comprehensive Competency-based In-service Training (CCBIT) system that has been adopted to train all child welfare employees in 24 states and six Canadian provinces. Typically, new workers are required to complete courses on the core competencies during their first year of employment. The CCBIT system focuses on 52 competencies in four areas that are deemed crucial to current child welfare practice. For example, the core curriculum covers competencies on (1) the legal aspects of child protection, (2) family-centered 
child protective services, (3) case planning/ casework, and (4) the effects of abuse and neglect on child development. Specialized competencies have also been developed on several topics such as adoption/foster care, working with adolescents, sexual abuse, intake/ assessment, interventions, substance abuse, and others. Despite the comprehensiveness of this system, however, it is still somewhat limited in addressing transfer of learning issues and does not include the most recent research in child welfare.

Although the CCBIT system is widely used by states to prepare child welfare workers, social work programs that train MSW students who plan to enter the child welfare field have not previously adopted these materials. The use of these materials by The Ohio State University's College of Social Work may serve as a model for other social work programs interested in using the Institute for Human Services/CWLA materials.

In addition to standard MSW requirements, a four-course series covering the core competencies (Child and Family Policy, Advanced Child Welfare Practice (I and II), and an Integrative Seminar on Child Welfare) was required of trainees. While the Field Guide to Child Welfare (Rycus \& Hughes, 1998) provided a competency-based foundation, course content was supplemented with recent empirical work in child welfare and a critical analysis of current trends in child welfare services. In addition, the curriculum was integrated with the field practicum component of the MSW program to ensure that students acquired the knowledge and skills needed to move quickly into child welfare positions upon graduation. The field practicum experience was supplemented with quarterly meetings including students, faculty members, and field instructors to discuss issues related to the integration of classroom and field learning. Through these efforts, trainees in the program were expected to increase their knowledge and skill competencies for provision of child welfare services, begin to think critically about current practices in child welfare, transfer their learning from the classroom to applied settings, and obtain employment in child welfare after completing the MSW program at OSU.

To ensure continued collaboration throughout the traineeship, an advisory board was convened on a quarterly basis. The advisory board consisted of the authors of the Field Guide to Child Welfare (Rycus \& Hughes, 1998), county child welfare administrators, staff members from private child welfare advocacy groups, and university faculty members. The Board met quarterly to review the program's activities and discuss possible modifications to the curriculum or field experience.

Other components of the program included devising and implementing an evaluation of the training and disseminating information about the program to interested parties. The trainees were evaluated in terms of knowledge acquisition, skill development, attitudes about the child welfare profession, critical thinking skills, sensitivity to cultural diversity, and post-graduation child welfare employment. Skill development was evaluated primarily through the field evaluation process and is not reported here. Likewise, critical thinking skills were evaluated primarily through graded classroom assignments. Evaluation of the trainees' sensitivity to cultural diversity is reported elsewhere (Vonk \& Curtis, under review). 
The remainder of this report focuses on the evaluation of knowledge acquisition, child welfare attitudes, and child welfare employment one year after graduation.

\section{METHODS}

\section{Design and Selection of Students}

This study utilized a quasi-experimental pre-test-post-test comparison group design with a one-year follow-up. An additional follow-up interview with the trainees was conducted in 2002 (three years after the program for the 1999 cohort and two-years after the program for the 2000 cohort). The two groups used for initial pre-test-post-test comparison were second year MSW students selected for the training program $(n=14)$ and a group of second year MSW students not involved in the training program who volunteered to complete the outcome evaluation instruments ( $n=14)$.

All eligible MSW students received solicitation letters describing the child welfare-training program. The solicitation included information about the components of the training program and the expectation that trainees would work in the field of child welfare for one year upon completing the MSW degree. Interested students were instructed to indicate ways in which the training program would fit with their future study and career plans. Students were then selected for thetraining group based on application letters reviewed by three faculty members involved with implementing the training grant. As a result, in each of the two years, seven second year MSW students were selected to receive competency based child welfare training.

Comparison group participants also were recruited through letters circulated to all eligible MSW participants. The recruitment letters contained information about the time commitment necessary for the study and a monetary incentive upon completing the questionnaires. In each of the two years, seven second-year MSW students volunteered for the comparison group that received only the traditional second-year MSW curriculum. Thus, the 14 trainees were compared to 14 non-trainees.

\section{Measures}

Measurement of the students' child welfare knowledge was based on the training materials developed by the Institute for Human Services (IHS) and the Child Welfare League of America (CWLA). Knowledge acquisition was measured using the 81-item questionnaire that was developed for training purposes by the authors of the Field Guide to Child Welfare (Rycus \& Hughes, 1998). Specifically, the comprehensive 81-item child welfare knowledge questionnaire is divided into four sections that correspond to the organization of materials in the Field Guide: (1) "Family-Centered Child Protective Services"; (2)“Case Planning and FamilyCentered Casework in Child Protective Services"; (3) "The Effects of Abuse and Neglect on Child Development"; and (4) "Separation, Placement, and Reunification." A variety of questions were used to gauge student knowledge in each of the aforementioned areas.

Participant attitudes and beliefs about child welfare practice were assessed using a 20-item questionnaire developed by the first author. The attitude and 
belief scale was designed to assess student attitudes and beliefs, both about child welfare as a career choice and about working with child welfare clients. A fivepoint Likert scale was used to assess student attitudes and beliefs ( 1 =strongly disagree and 5=strongly agree). Sample items related to working with child welfare clients include, "Sometimes the general interests of the family should supersede the interests of the child" and "Child abuse is basically caused by lack of parenting skills or flawed thinking in the abuser." Sample items about child welfare as a field of practice included "It is highly unlikely that I will be working in the field of child welfare 10 years from now." and "Sooner or later most child welfare workers become disillusioned with their jobs."

Information about the post-graduate field of employment was obtained with a survey mailed exclusively to trainees one year following graduation from the program. Graduates of the training program were also contacted during the spring of 2002. In addition to questions about current employment, graduates reported their perceptions of the relevance and satisfaction with the child welfare-training program using the same Likert scale described previously.

\section{Procedure}

All training activities were offered during the second year of the MSW program. The tests were administered to the trainees and students in the comparison group at the beginning of training in the fall of 1998 and 1999 and at the end of training in the spring of 1999 and 2000. Follow-up surveys were mailed to graduates of the child welfare training one-year following graduation in the spring of 2000 and 2001. Also, post-graduates of the training program were contacted via the telephone in the spring of 2002.

Data were coded and entered into a database, and analyzed using SPSS 10.0.5. In order to describe the data obtained from the group of trainees and contrast it to the comparison group, univariate, bivariate, and multivariate statistics were calculated. The rationale for using descriptive and inferential statistics was based on uncovering statistically significant differences between the group of trainees and the comparison group. In particular, it was hoped that those who participated in the child welfare-training program would display greater gains in knowledge of and attitudes toward child welfare practice.

\section{RESULTS}

There were no significant demographic differences between the groups for age $\left(X^{2}(2)=9.44, p=66\right)$, gender $\left(X^{2}(1)=297, p=58\right)$, race $\left(X^{2}(2)=2.62, p=26\right)$, or years of experience in child welfare $\left(X^{2}(3)=3.39, p=33\right)$. A substantial majority of students involved in the study were Caucasian women. The majority of the students were in their twenties, with an age distribution that ranged from 22 to 58 years. With respect to years of experience in the child welfare profession, 23 participants reported no experience, while five reported having one to three years of experience.

Overall, descriptive data showed an increase in child welfare knowledge from pre-test to post-test scores for the trainees and the comparison group using the child welfare knowledge questionnaire. Specifically, the mean for the child wel- 


\begin{tabular}{|lrc|}
\hline Table 1: Demographic Characteristics of Participants & \\
\hline Characteristics & $\mathbf{n}$ & $\%$ \\
\hline Gender & & \\
Female & 24 & 85.7 \\
Male & 4 & 14.3 \\
Age (years) & & \\
22-30 & 22 & 78.6 \\
31-39 & 4 & 14.3 \\
$40-58$ & 2 & 7.1 \\
Race & & \\
White & 21 & 75.0 \\
African-American & 5 & 17.9 \\
Other & 2 & 7.1 \\
Years Experience & & \\
None & 23 & 82.2 \\
OneYear & 2 & 7.1 \\
Two Years & 2 & 7.1 \\
Three Years & 1 & 3.6 \\
\hline
\end{tabular}

fare training group increased from 53.42 correct answers at pre-test to 60.46 at post-test. This is an overall increase from $66 \%$ to $75 \%$ on the 81 -item welfare knowledge acquisition questionnaire. An increase in the number of correct answers also occurred in the comparison group from pre-test to post-test. The comparison group mean increased from 49.87 at pre-test to 55.08 at post-test, resulting in an overall increase from $62 \%$ to $68 \%$ on the 81 -item questionnaire. Despite the greater increase in knowledge scores among the trainees, independent t-tests uncovered no statistical significance from pre-test to post-test for trainee or comparison groups on the 81-item questionnaire, $\underline{t}(26)=1.08, p=28$; and $t(26)=1.06, p=29$; respectively. In addition, when controlling for the pre-test, the one-way Anova procedure uncovered no statistically significant difference between the two groups on child welfare knowledge at post-test, $F(1,26)=1.12$; $p=30$. The differences among mean scores did not produce a large enough effect to be detected within the limits of the statistical power.

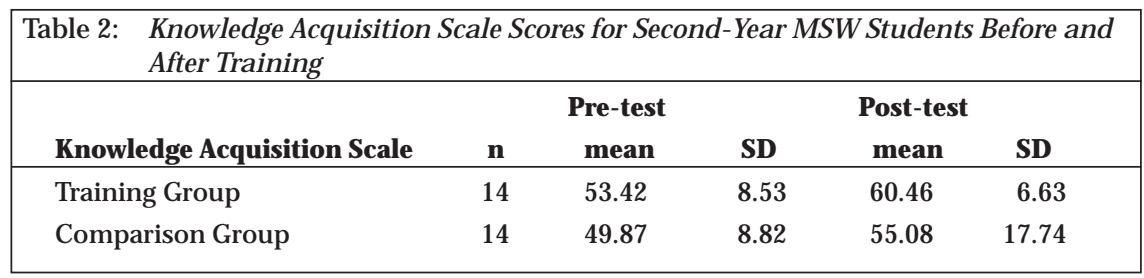

Although there was no statistically significant difference for either group from pre-test to post-test on the knowledge component of the study, independent ttests did uncover a statistical ly significant difference between the trainees and the comparison group concerning their attitudes towards the field of child welfare practice. Students in the training group had more positive attitudes about the profession of child welfare when compared to those students in the comparison group at post-test. On the other hand, there was no statistically significant differ- 
ence between the two groups on their attitudes towards child welfare clients at post-test.

$\begin{aligned} \text { Table 3: } & \text { Post-test Means for the Scales Measuring Attitudes About the Child Welfare } \\ & \text { Profession and Attitudes About Child Welfare Clients by Training Group and } \\ & \text { Comparison Group }(\mathrm{N}=28)\end{aligned}$

\begin{tabular}{|lcc|}
\hline Measure & CW Profession & CW Clients \\
Training Group & $3.08^{*}$ & 3.14 \\
Comparison Group & 1.72 & 3.07 \\
\hline Results of t-tests: ${ }^{*} p 01$. & & \\
\hline
\end{tabular}

As expected, it was found that students in the training group were more likely than their counterparts to actively seek positions in the field of child welfare at graduation. In fact, all but one of the students in the training group, as compared to only two of the students in the comparison group, reported the intention to seek employment in child welfare.

At the one-year post-graduation follow-up, we were able to contact 11 of the 14 trainees, all of whom completed follow-up questionnaires. All but two were employed in child welfare. At the two- or three-year follow-up, 12 of the 14 trainees were contacted by telephone. All but two of the 12 contacted reported currently being employed in child welfare. Specifically, all those in the two-year follow-up cohort were employed in child welfare; whereas, all but two in the three-year follow-up cohort were employed in child welfare. For analysis purposes, missing data were replaced by the mean of the distribution; an acceptable procedure when the replaced data do not exceed $15 \%$ for a particular case and/ or variable (George \& Mallery, 2001).

One-year follow-up also revealed favorable outcomes regarding the training participants' attitudes about the field of child welfare practice and child welfare clients. In fact, comparisons from post-test to one-year follow-up uncovered that training participants had sustained a positive attitude in each area over the 12month time period. To the point, training group participants reported a minimal decrease of only 0.74 regarding their attitudes toward child welfare practice and a minimal decrease of only 0.70 regarding their attitudes toward child welfare clients. Thus, the trainees maintained moderate to strong agreement with positive attitudes toward the child welfare profession and clients.

Post-test to one-year follow-up comparisons also revealed favorable outcomes concerning trainee satisfaction and trainee perception of relevance of the training they received. Specifically, trainee satisfaction remained very high, with only a minimal decrease of 0.35 . More importantly, the relevance of programmatic training to child welfare practice also remained very high, with a decrease of only 0.44. Favorable outcomes were also uncovered at the two- or three-year followup. In fact, t-test for paired samples uncovered a statistically significant improvement on mean scores from the one-year follow-up to the two- or three-year follow-up concerning the overall relevance of programmatic training t $(13)=2.37$; $p<05$, and overall satisfaction of programmatic training t $(13)=2.34 ; p<05$. 


\begin{tabular}{|c|c|c|c|c|c|c|}
\hline \multirow[b]{2}{*}{ Measure } & \multicolumn{2}{|c|}{$\begin{array}{l}\text { Post-test } \\
\text { Score }\end{array}$} & \multicolumn{2}{|c|}{$\begin{array}{l}\text { One-year } \\
\text { Follow-up }\end{array}$} & \multicolumn{2}{|c|}{$\begin{array}{l}\text { Two-year } \\
\text { Follow-up }\end{array}$} \\
\hline & $M$ & SD & $M$ & SD & $M$ & SD \\
\hline $\begin{array}{l}\text { Satisfaction with } \\
\text { Training }\end{array}$ & 2.92 & 2.01 & 2.57 & 1.73 & $3.50^{*}$ & .65 \\
\hline $\begin{array}{l}\text { Relevance of } \\
\text { Training }\end{array}$ & 2.85 & 1.95 & 2.41 & 1.58 & $3.71^{*}$ & .82 \\
\hline
\end{tabular}

At the post-test and follow-up interviews participants were also asked their opinions about the Field Guide to Child Welfare The respondents consistently reported that the books were clearly written, easy to read, relevant, and useful. The limitations mentioned by the participants focused on the cost of the fourvolume set (about \$120) and the difficulties they experienced transferring the information from the books to "real-life" situations.

\section{DISCUSSION}

The results of this study suggest that although child welfare trainees gained knowledge about child welfare practice, they did not do so at a rate statistically significantly greater than a group of students in the standard MSW program. The trainees did, however, show a more positive attitude toward the field of child welfare as a career than did the comparison group. Also, at one year and then again at either two or three years post-graduation, a high percentage of the former trainees were employed in child welfare with the intention of staying in the field for at least five more years. In addition, they reported the perception that most aspects of the training experience were satisfying and, more importantly, relevant to their current work.

Before interpreting the results further, important limitations of this study should be mentioned. First, the small sample size seriously limits the ability to generalize the results. In addition, bias in the non-random sample selection limits the ability to draw firm conclusions about the effects of the training intervention. Obviously, students in the training group indicated high interest in the field of child welfare prior to training. Just as importantly, students in the comparison group were exposed to information about child welfare through other classes in the MSW program, or in a few cases, by electing to participate in one of the classes required of the trainees. Finally, the instruments lack standardization. As such, the nominal increase in knowledge and the lack of statistical differences between the groups may be the result of learning stimulated by the administration of the pre-test, the overlap of knowledge acquired from other MSW courses taken by the comparison group, or insufficient statistical power to detect differences. In spite of these limitations, the results suggest additional support for training social workers to work in the field of child welfare. 
Related to concerns about the professional and educational preparation of social workers for child welfare careers (Gleeson, et al., 1993; Lieberman, et al., 1988; Hopkins, et al., 1999), these results appear to have provided both a reason for hope and continued concern. First, related to the perceived need for more professionally trained social workers in child welfare, these results suggest that the TitleIV-E funding did support the professional education of 14 social workers, the majority of whom were employed in the field of child welfare two to three years after graduation. Similar to the findings of Robin and Hollister (2001), these results were promising also in terms of the retention of child welfare workers whose education was funded by Title IV-E money. All of those employed in child welfare one year post-graduation reported the intention of staying there. The interpretation of the results in light of the criticism that social work education has not been relevant to the work of child welfare may also be seen in a positive light. Most of those trained perceived the "training overall" to be moderately to very relevant to their work even after two or three years had elapsed.

In spite of these positive findings, the students' modest gain in knowledge about child welfare remains a concern, both in terms of curriculum planning and research methodology. Although this study did not address curriculum, per se, we have given thought to this concern and speculate that curriculum might be strengthened in several ways. First, trainees might benefit from a curriculum that could be tailored to the individual's needs based on pre-training testing of knowledge and skills. Many of the trainees began the program with work experience in child welfare. As such, they entered the program with varying levels of knowledge about child welfare. Learning might be maximized by tailoring learning objectives and related activities for each of the overall program goals according to the needs of each student. For example, a student with a high baseline of knowledge and skills in the area of adoptive placement may benefit from a greater focus on other areas of child welfare such as child protective investigation.

Other curriculum changes might include those that focus on transfer of learning. For example, use of classroom time could place a greater emphasis on experiential learning activities that require analysis and synthesis of information. In addition, classroom instructors and field supervisors might collaborate to create direct ties between field and classroom learning through the use of case-studies and assignments that require integration of classroom knowledge and field experience.

Regarding future research on child welfare training effectiveness, while there is accumulating evidence to support the effectiveness of training social workers for the demands of child welfare work (Hopkins, et al., 1999; Robin \& Hollister, 2001; Rose, 1999), the studies, including this one, have all been exploratory in nature. Furthermore, methodologically rigorous research is important in order to help guide Title-IV-E appropriations and determine whether participants are adequately trained to meet the needs of clients. Samples should be sufficiently large that small effect sizes might be detected. Multi-site training projects such as one currently in planning stages in the state of Ohio potentially would provide a large group of trainees. A multi-site program would also provide the possibility of interesting comparisons of the effects of various learning activities related to consis- 
tent goals among the sites. This would, of course, require careful operationalization of the training interventions. Finally, future research must also include the use of meaningful comparison groups. At the very least, the students in the comparison groups should not be exposed to coursework designed specifically for trainees.

While this study found that a small cohort of Title-IV-E funded child welfare trainees made modest gains in knowledge, maintained favorable attitudes about the child welfare profession, and for the most part, remained employed in child welfare for up to three years following training, it is clear that further evaluation is needed. As others have observed (Gleeson, et al., 1993), the complexity of problems encountered by child welfare workers requires increasing levels of knowledge and skills. Future child welfare professionals must be armed with the knowledge and skills needed to meet the demands of their jobs. Competency-based child welfare training curriculums and educational collaborations must be strengthened and rigorously tested to determine whether those who participate in training are better able to deliver child welfare services.

\section{References}

Anderson D. (1994). Coping strategies and burnout among veteran child protection workers. Doctoral dissertation, University of South Carolina.

Cicero-Reese, B., \& Black, P. (1998). Research suggests why child welfare workers stay on the job. Partnerships for Child Welfare, 5(5), 8-9.

Curtis, P., \& Boyd, J. (1996). 1995 salary study. Washington, D.C.: Child Welfare League of America.

Daly, D., Dudley, D., Finnegan, D., \& Christiansen, J. (2000). Staffing child welfare services in the new millennium. San Diego, CA: Network for Excellence.

George, D., \& Mallery, P. (2001). SPSS for Windows: A simpleguideand reference. Boston: Allyn and Bacon.

Gleeson, J.P., Smith, J.H., \& Dubois, A.C. (1993). Developing child welfare practitioners: Avoiding the single-solution seduction. Administration in Social Work, 17(3), 21-37.

Glisson, C., \& Hemmelgarn, A. (1998). The effects of organizational climate and interorganizational coordination on the quality and outcomes of children's service systems. Child Abuseand Neglect, 22(5), 401421.

Guterman, N., \& Jayaratne, S. (1994). “Responsibility at-risk:” Perceptions of stress, control and professional effectiveness in child welfare direct practitioners. Journal of Social ServiceResearch, 20(1/2), 99-120.

Harrison, S. (1995). Exploration of factors related to intent to leave among child welfare caseworkers. Doctoral dissertation, The Ohio State University.

Hopkins, K.M., Mudrick, N.R., \& Rudolph, C.S. (1999). Impact of university/agency partnerships in child welfare on organizations, workers, and work activities. Child Welfare, 78, 749-773.

Jones, L. (2002, February). Retaining Title IV-E graduates in child welfare: A follow-up study. Paper presented at the Annual Program Meeting of the Council on Social Work Education, Nashville, TN.

Larner, M., Stevenson, C., \& Behrman, R. (1998). Protecting children from abuse and neglect: Analysis and recommendations. TheFuture of Children, 8(1), 4-22.

Lieberman, A.A., Hornby, H., \& Russell, M. (1988). Analyzing the educational backgrounds and work experiences of child welfare personnel: A national study. Social Work, 33, 485-489.

Olsen, L., \& Holmes, W. (1982). Educating child welfare workers: The effects of professional training on service delivery. Journal of Education for Social Work, 18, 94-102.

Pecora, P., Briar, K., \& Zlotnik, J. (1989). Addressing the program and personnel crisisin child welfare. Silver Springs, MD: NASW. 
Robin, S.C., \& Hollister, C.D. (2001). Career paths and contributions of four cohorts of IV-E funded MSW child welfare graduates. Journal of Health and Social Policy.

Rose, S.J. (1999). Educating adult learners for child welfare practice: The Wisconsin experience with Title IV-E. Journal of Teaching in Social Work, 18(1/2), 169-183.

Rycraft, B. (1994). The party isn't over: The agency role in the retention of pubic child welfare workers. Social Work, 39, 75-80.

Rycus, J.S., \& Hughes, R.C. (1998). Field guide to child welfare Washington, D.C.: CWLA Press.

Vinokur-Kaplan, D., \& Hartman, A. (1986). A national profile of child welfare workers and supervisors. Child Welfare, 65, 323-335.

Vonk, M.E., \& Curtis, C.C. (under review). Pilot test of a learning experience designed to engage social work students in the development of racial awareness.

Zlotnik, J.L., \& Cornelius, L.J., (2000). Preparing social work students for child welfare careers: The use of Title IV-E training funds in social work education. The Journal of BaccalaureateSocial Work, 5(2), 1-13.

\section{Author's Note:}

Address correspondence to: M. Elizabeth Vonk, MSW, Ph.D., Associate Professor, School of Social Work, University of Georgia, Tucker Hall, Athens, GA 30602, USA. E-mail: bvonk@uga.edu 